\title{
REFORMAS INSTITUCIONAIS E AS RELAÇÕES ENTRE A POLÍCIA E A SOCIEDADE EM NOVA IORQUE
}

\author{
Arthur T. M. Costa*
}

\begin{abstract}
Resumo: O controle da atividade policial é um dos aspectos fundamentais dos regimes democráticos. É necessário, portanto, refletir sobre os tipos de medidas propostas para controlar as polícias. Visando contribuir para o debate, este artigo analisa algumas reformas institucionais, internas ou externas ao Departamento de Polícia de Nova Iorque e seus efeitos sobre as relações entre a polícia e a sociedade. Verificamos que as reformas que visaram modificar determinadas práticas policiais institucionalizadas tiveram mais sucesso do que aquelas que buscaram punir desvios individuais de comportamento.

Palavras-chave: violência policial, controle das atividades policiais, democracia, New York Police Department, polícia.
\end{abstract}

\section{Introdução}

A relação entre as polícias e a sociedade têm sido objeto de debate nas sociedades democráticas. As instituições policiais são aquelas organizações destinadas ao controle social com autorização para utilizar a força, caso necessário (Bayley, 1975). Nos regimes democráticos, a atividade policial requer um equilíbrio entre o uso da força e o respeito aos direitos individuais. Nesse sentido, podemos afirmar que a especificidade da atividade policial nos regimes democráticos é a necessidade de controlar e limitar o uso da força.

* Doutor em Sociologia e professor do Departamento de Sociologia da Universidade de Brasília.

$\mathrm{O}$ autor agradece à Capes pelo apoio financeiro, sem o qual não seria possível realizar esta pesquisa.

Artigo recebido em 29 jan. 2004; aprovado em 04 jun. 2004. 
Nos últimos 20 anos, as recém-(re)estabelecidas democracias da América Latina enfrentaram o desafio de reformar suas forças policiais. Os esforços concentraram-se na criação de mecanismos institucionais de responsabilização e controle, estimulando as polícias a se submeterem ao Estado de Direito e a respeitar as liberdades civis. Processos de reformas foram iniciados na Argentina, Brasil, Colômbia, El Salvador, Guatemala, Haiti, Honduras, México e Nicarágua. ${ }^{1}$ Apesar dos esforços, as reformas implantadas não lograram o êxito esperado. Abusos de autoridade e violência continuam sendo freqüentes nos contatos entre os policiais desses países e a população.

É necessário, portanto, refletir sobre os tipos de medidas propostas para controlar as polícias. Visando contribuir para o debate, este artigo analisa algumas reformas institucionais, internas ou externas ao New York Police Departament (NYPD - Departamento de Polícia de Nova Iorque), e seus efeitos sobre as relações entre a polícia e a sociedade. Neste estudo, não tomamos um modelo ideal de polícia por entender que a organização policial e sua relação com a comunidade dependem das características sociais, econômicas, políticas e culturais das sociedades nas quais estão inseridas.

O caso de Nova Iorque mostra-nos que algumas mudanças institucionais tiveram mais sucesso do que outras no que se refere ao controle da atividade policial. E tiveram, portanto, diferentes conseqüências para as relações entre polícia e sociedade. Analisaremos: a) as mudanças na legislação criminal; b) a introdução das normas de conduta; c) a adoção de novas estratégias de policiamento (policiamento comunitário e tolerância zero); d) a criação e expansão do papel do órgão de controle externo; e) o papel do sistema judiciário e f) a criação de procuradores federais para supervisionar o trabalho policial.

\section{Por uma análise institucional da violência policial}

A análise do comportamento policial não pode ser dissociada do estudo das estruturas políticas, sociais, culturais e normativas que 
moldam esse comportamento. O comportamento violento de determinados policiais não pode ser explicado simplesmente a partir das motivações individuais. Há uma série de normas sociais, leis e regulamentos que norteiam esse comportamento, seja coibindo determinadas ações, seja incentivando outras. Assim, rejeitamos a explicação a partir da idéia de "maçãs podres", recorrente no discurso de algumas autoridades políticas e policiais. De acordo com essa idéia, a violência policial seria conseqüência da ação de alguns maus policiais que deveriam ser demitidos, sob o risco de contaminarem o resto da corporação. Não há dúvidas de que policiais violentos devam ser afastados, mas a questão que colocamos neste artigo vai além do nível de análise individual. Interessa-nos entender como tais comportamentos são permitidos ou tolerados e não as motivações individuais desse comportamento. Nesse sentido, nossa análise concentra-se nas instituições, ou, como prefiro, nas práticas institucionalizadas.

Pode-se dizer que o interesse das ciências sociais pelas instituições ressurgiu no final da década de 70. De alguma forma, esse movimento representou uma reação à revolução comportamental dos anos 50 e 60, que via a ação política e o comportamento econômico como simples conseqüência agregada dos comportamentos individuais (March e Olsen, 1984). Do ponto de vista comportamentalista, as instituições eram retratadas como simples arenas dentro das quais os indivíduos manifestavam seu comportamento político. $\mathrm{O}$ ponto de partida dos novos estudos sobre instituições, também chamados de novo institucionalismo, é sua crítica às análises dos comportamentos observáveis, uma vez que não acreditam que sejam suficientes para explicar o comportamento individual. $\mathrm{O}$ comportamento individual acontece dentro de limites (leis, regras, normas sociais, etc.) estabelecidos pelas instituições e, portanto, deve ser explicado por meio delas.

São dois os aspectos principais da crítica institucionalista à abordagem comportamentalista. O primeiro refere-se à suposição de que o comportamento político reflete as preferências pessoais. De acordo com a abordagem comportamental, uma vez que as verdadeiras 
preferências pessoais não podem ser observadas, a ênfase deve recair sobre o comportamento que "expressa" tais preferências (Immergut, 1998).

A crítica institucionalista recai na distinção entre preferência real e comportamento expresso. Existem inúmeras circunstâncias que condicionam o comportamento individual, distanciando-o das reais preferências do indivíduo. Os institucionalistas buscam analisar por que um determinado ator político escolhe uma opção em particular e não outra igualmente possível. Aqui, as opções adotadas (comportamentos expressos) são tomadas como resultado de uma estrutura política e não como seu ponto de partida.

No caso das polícias, importa entender por que os membros de determinados departamentos de polícia optam mais freqüentemente pelo uso da violência contra os cidadãos. Não nos interessa saber se o policial A ou B quis ou não agir violentamente, mas sim como isso foi possível. Assim, é necessário concentrar a análise nos mecanismos de controle da atividade policial, bem como entender as razões políticas e sociais que levaram à introdução desses mecanismos.

\section{Polícia e sociedade em Nova Iorque}

A relação entre o NYPD e a comunidade têm sido marcada por tensões e conflitos sociais. Há uma longa história de violência policial, segregação social e discriminação contra minorias étnicas. Embora a tensão seja um traço marcante nas relações entre o $N Y P D$ e a sociedade, inúmeras mudanças institucionais têm ocorrido desde o início da década de 70, gerando efeitos importante nessas relações.

Em 1970, após uma série de escândalos de corrupção envolvendo policiais, o prefeito da cidade, John Lindsay, estabeleceu um grupo de trabalho para investigar o assunto e propor soluções. $\mathrm{O}$ grupo, que ficou conhecido como a Comissão Knapp, trabalhou dois anos e meio realizando investigações e ouvindo inúmeros policiais, políticos e lideranças comunitárias. No seu relatório final, divulgado em 1972, a comissão apontou: 
Nós verificamos que a corrupção é corrente. Ela toma várias formas, dependendo da atividade envolvida, parece mais sofisticada entre os policiais designados para fiscalizar o jogo. Nas cinco divisões policiais onde nossas investigações se concentraram, nós encontramos um padrão extremamente institucionalizado de corrupção. (Knapp Commission, 1972, p. 1) $)^{2}$

Além da corrupção, as relações entre a polícia e a comunidade eram marcadas também pela violência dirigida contra determinados segmentos sociais. Estudando casos de abusos policiais entre 1966 e 1967, em Nova Iorque, Paul Chevigny (1969) concluiu que o uso de violência contra cidadãos que desafiassem a autoridade policial era prática corrente no departamento de polícia. O uso dessa violência era justificado pelas autoridades políticas e policiais como necessária para a manutenção da lei e da ordem. As vítimas mais comuns desse tipo de violência eram pessoas pobres, pertencentes a minorias socialmente discriminadas, como negros, latinos e homossexuais. Qualquer membro dessas minorias que desafiasse de alguma forma a autoridade reivindicada pelos policiais estaria sujeito a punições violentas que variavam desde o uso de linguagem agressiva até o uso da força letal. O uso da violência contra os segmentos mais desprivilegiados da população era prática institucionalizada, uma vez que fazia parte das estratégias de ação disponíveis.

Passados mais de trinta anos do relatório Knapp e do estudo de Chevigny, a relação entre o NYPD e a sociedade nova-iorquina continua tensa. A corrupção continua sendo um problema sério, como apontou o relatório da comissão Mollen (Mollen Commission, 1994). Além das antigas formas de corrupção detectadas pela comissão Knapp, novas formas de desvio de conduta foram verificadas, normalmente ligadas ao narcotráfico.

Com relação à violência policial, essa parece ter perdido seu caráter institucionalizado como apontam David Bayley e James Garafalo. Depois de estudarem inúmeras situações de potencial conflito entre policiais e cidadãos, os autores concluíram que o recurso à violência, como estratégia de ação, é caso raro, uma vez que menos 
de $3 / 4$ dos cerca de 500 incidentes potencialmente violentos observados resultaram em algum tipo de violência:

os policiais raramente deparam-se com a violência nos seus encontros com o público. Eles são freqüentemente chamados em situações onde a violência já ocorreu e que é tampouco dirigida contra eles e como resultado produz poucas baixas e feridos tanto na polícia quanto no público. (Bayley \& Garafalo, 1989, p. 6)

Embora não se possa afirmar que a violência policial continue sendo uma prática institucionalizada no NYPD, casos como o de Abner Louima e Amadou Diallo deixam bem claro que ela não deixou de existir. Louima fora torturado e sodomizado dentro de um distrito policial e Diallo morto por quatro policiais com 41 tiros, apesar de não haver nenhuma grave suspeita contra ele. Nos dois casos, bem como na maioria nos demais casos relatados por entidades de proteção aos direitos humanos, as vítimas eram negras ou latinas. Se casos de violência policial como estes não são mais freqüentes, o mesmo não se pode dizer com relação a outras formas de arbitrariedade policial. Entidades como Amnesty International, Human Rigths Watch, Police Watch e New York Civil Liberties Union, têm frequientemente denunciado casos de desvio de conduta policial, como abuso de autoridade, desrespeito aos cidadãos e uso de linguagem ofensiva (Anistia Internacional, 1996; New York Civil Liberties Union, 1998; Green et al., 2000).

\section{A lei e os interrogatórios policiais}

O sistema jurídico norte-americano, diferente do brasileiro, é baseado principalmente na jurisprudência das cortes. Em outras palavras, as decisões dos juizes e dos tribunais reinterpretam freqüentemente o significado das leis. Outra característica do sistema jurídico americano é a sua extrema descentralização. O sistema americano concede grande autonomia decisória aos Estados, cabendo à corte federal pronunciar-se sobre poucos casos com base na sua interpretação da Constituição Federal. 
No que diz respeito às polícias, inúmeras decisões da suprema corte norte-americana têm afetado suas atividades. Na maior parte, são decisões que dizem muito mais respeito aos procedimentos adotados pela polícia do que propriamente à legislação criminal. Desde a década de 60, a corte federal tem tomado decisões sobre a constitucionalidade de determinadas práticas policiais.

Em 1959, no caso Spano vs New York, a suprema corte reafirmou suas antigas decisões sobre a aceitabilidade de confissões nos processos judiciais (Skolnick \& Fyfe, 1993). Em 1936, a corte já havia decidido que somente as confissões voluntárias poderiam ser aceitas pelas cortes de justiça. A questão era entender na prática a diferença entre confissão voluntária e coercitiva. No caso Spano vs New York, a corte federal decidiu impor mais limites à utilização de interrogatórios para obtenção de confissões. A questão não recaía simplesmente sobre o uso de métodos ilegais por parte da polícia, mas sobre a própria utilização de interrogatórios como prática policial. Nesse sentido, decidiu-se que uma confissão só poderia ser aceita como válida se fosse voluntária, ou seja, livre de qualquer tipo de constrangimento físico ou psicológico. Assim, a própria prática de deter algum suspeito para interrogatório passou a ser vista como uma forma de constrangimento psicológico (Kamisar, 1990).

Em 1966, novamente a suprema corte federal voltou a pronunciar-se sobre casos de custódia policial. No caso Miranda vs Arizona, estabeleceram-se algumas regras básicas sobre interrogatórios (Skolnick \& Fyfe, 1993). Primeiro, todos os suspeitos teriam direito a um advogado imediatamente após terem sido informados dos seus direitos constitucionais. Segundo, uma vez invocado o seu direito de permanecer em silêncio, o suspeito não poderia mais ser questionado. E finalmente, todos deveriam ser informados desses direitos.

Se na década de 60, a suprema corte passou a adotar uma postura mais rígida com relação aos procedimentos policiais, na década de 90 parece ter começado a aceitar determinados procedimentos. $\mathrm{Na}$ decisão sobre o caso Fulminante vs Arizona, a corte julgou válida a 
confissão obtida através de negociação que incluía a garantia da integridade física do suspeito (Skolnick e Fyfe, 1993). No caso, os policiais prometeram ao suspeito que zelariam pela sua integridade física enquanto este estivesse preso. De certa forma, esta medida reinterpretou a decisão de 1959 sobre o uso de coação para obtenção de confissões.

Em entrevista dada ao autor, Jerome Skolnick, estudioso das polícias norte-americanas, afirmou que desde a introdução destas restrições, os casos de tortura em interrogatórios policias têm sido raros. De fato, os casos de tortura denunciados pela mídia e pelas organizações de direitos humanos não dizem respeito aos interrogatórios, mas sim a discriminação contra minorias éticas.

Embora as decisões da suprema corte de justiça americana tenham servido para restringir o uso de interrogatórios nas investigações policiais, nem todas as decisões judiciais conseguem mudar determinadas práticas policiais. Nos últimos anos, a justiça federal tem se manifestado sobre o uso de animais e instrumentos de alta tecnologia nas operações de busca e apreensão. ${ }^{3}$ Como apontam Skolnick e Fyfe, o efeito dessas decisões têm sido bastante variado, uma vez que não são muito claras a respeito de como a polícia deveria proceder. Na prática, as decisões judiciais sobre conduta policial só têm efeitos concretos quando os departamentos de polícia decidem reformular suas normas de conduta (Skolnick \& Fyfe, 1993).

\section{Normas de conduta e o uso da força letal}

Boa parte das estratégias adotadas para controlar a atividade policial baseia-se em códigos de conduta, manuais de treinamento e no sistema de supervisão policial. Uma das mais bem-sucedidas iniciativas nesse campo foi a restrição ao uso da força letal por parte dos departamentos de polícia norte-americanos.

Embora o problema do uso de armas de fogo seja muito antigo, até o inicio da década de 70, quase nenhum departamento de polícia norte-americano possuía normas internas específicas para controlar o 
uso da força letal. ${ }^{4}$ Até então, a polícia podia usar a força letal para impedir a fuga de qualquer criminoso, independente se o crime envolvesse violência ou não.

Foi no contexto dos movimentos dos direitos civis das décadas de 50 e 60 que alguns grupos começaram a pressionar as autoridades públicas para que impusessem maiores restrições ao uso da força letal. As pressões vinham das mais variadas fontes, tais como associações de advogados e universidades, além dos grupos e lideranças ligados ao movimento de direitos civis. Sustentava-se que só a iminente ameaça de vida, seja de um policial ou de outro cidadão, poderia justificar o uso da força letal. As polícias e grupos ligados a ela argumentavam que tais restrições impostas à atividade policial iriam diminuir a sua eficiência (Geller \& Scott, 1992).

O NYPD foi uns dos primeiros departamentos de polícia norteamericanos a adotar normas de conduta para limitar o uso da força letal. Em 1972, sob a iniciativa do comissário de polícia Patrick Murphy, estabeleceram-se regras claras para restringir o uso de armas de fogo no departamento, dentro da filosofia de proteção à vida. As normas de conduta estabeleceram cinco estágios gradativos para o uso da força que, dependendo das circunstâncias podem ser reduzidos; são eles:

1) persuasão verbal;

2) uso de força física;

3) uso de armamento não letal, como sprays de pimenta;

4) uso de armas de impacto, como cacetetes e bastões elétricos; e

5) uso de armas de fogo, que só podem ser utilizadas quando a vida de um policial ou de outra pessoa estiver em perigo.

As normas também estabeleceram que lanternas, rádios e revólveres não foram desenhados como armas de impacto, portanto não podem ser empregadas como tal em circunstâncias normais. Além disso, os regulamentos da polícia estabelecem que qualquer policial envolvido num incidente tem a obrigação de fazer valer tais normas 
de conduta, impedindo o abuso de força (NYPD, 2000; Anistia Internacional, 1996).

A partir dessas normas de conduta, foram redefinidas as técnicas de ação utilizadas pela polícia e os programas de treinamento. Foram também adquiridos armamentos não-letais, como bastões elétricos e sprays de pimenta. Além disso, criou-se o Firearms Discharge Review Board, encarregado de investigar todos os incidentes policiais envolvendo disparo de armas. Murphy também passou a atribuir responsabilidade direta aos comandantes de distritos policiais pelos incidentes com armas de fogo, de forma que as restrições ao uso da força letal passaram a ser uma preocupação do departamento de polícia.

Os resultados fizeram-se sentir gradualmente. O número de civis mortos pela polícia caiu de 93, em 1972, para 25, em 1980. A partir daí, a taxa média de civis mortos pela polícia tem se mantido nesse nível. A relação entre o número de civis mortos pela polícia e o total de homicídios também caiu significativamente (Figura 1). Em 1972, os número de pessoas mortas pela polícia de Nova Iorque representava 6,3\% do total de homicídios ocorridos no mesmo ano. Em 1990, essa relação tinha diminuído para 1,9\% do total de homicídios ocorridos na cidade.

\section{Figura 1 - Proporção entre Civis Mortos pela Polícia e Total de Homicídios em Nova Iorque}

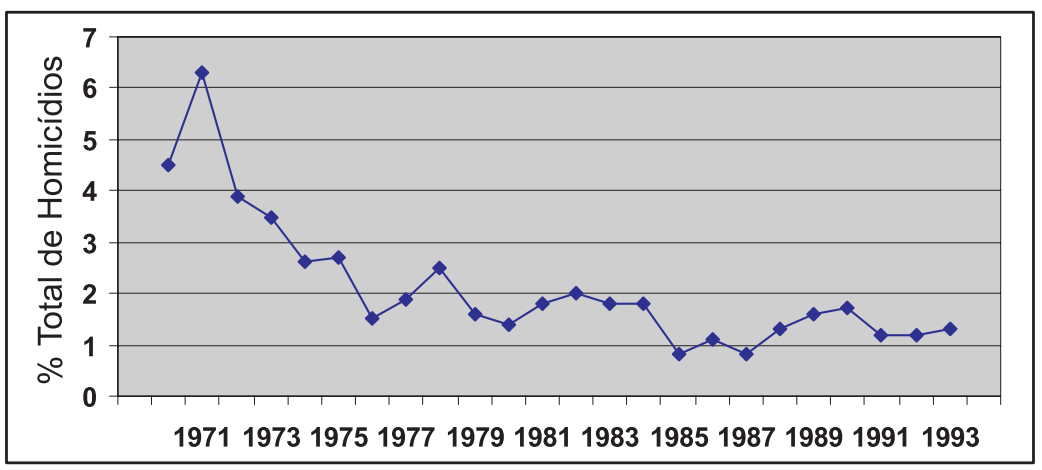

Fonte: Geller \& Scott, (1982), Chevigny (1995) e FBI, Uniform Crime Reports, 2000. 
A redução no número de civis mortos pela polícia deveu-se a dois fatores. Primeiro, graças ao estabelecimento de normas claras de conduta, foi possível adequar as técnicas de ação e o treinamento à política de proteção à vida implantada por Murphy. Segundo, com a criação de mecanismos de supervisão e a responsabilização dos chefes imediatos foi possível tornar essas normas efetivas (Fyfe, 1993).

Dado o sucesso das medidas adotadas para controlar o uso de armas de fogo, outras normas de conduta foram implantadas, por exemplo: normas para custódia de prisioneiros, para entrar em domicílios e para lidar com rebeliões nas prisões e cadeias da cidade.

\section{O policiamento comunitário em Nova Iorque}

A partir da década de 80, o desencantamento com as antigas estratégias de policiamento, tais como policiamento motorizado, resposta rápida e investigação criminal, tornou-se corrente entre os especialistas norte-americanos da área de segurança pública. Novas estratégias, visando alterar o papel das polícias no controle social, bem como as relações entre a polícia e a sociedade, passaram a ser repensadas. Isso resultou na formulação de uma nova filosofia de emprego das forças policiais que passou a ser conhecida como policiamento comunitário. Basicamente, essa nova filosofia de policiamento enfatizava a necessidade de um maior envolvimento da sociedade nas políticas de segurança pública, a fim de realizar um controle social democrático. Para tal, destacava-se a necessidade de mudanças nas relações das forças policiais com suas respectivas comunidades, o que implicaria profundas mudanças organizacionais, políticas e sociais.

Seguindo a tendência nacional, o NYPD implantou em 1984 um programa piloto de policiamento comunitário chamado Community Patrol Officer Program (CPOP) a partir de um estudo solicitado ao Vera Institute of Justice, uma organização nãogovernamental da cidade de Nova Iorque. Inicialmente implantado no $72^{\circ}$ Distrito Policial no Brooklyn, em 1988 o programa foi 
expandido para todos os demais distritos policiais da cidade. A adoção dessa nova estratégia de atuação trouxe reflexos importantes para as relações entre a polícia e a comunidade como veremos a seguir.

Basicamente, o CPOP foi desenhado para funcionar como uma unidade especial dentro de um distrito policial. Normalmente consistia de 10 policiais (Community Patrol Officers - CPO's), supervisionados por um sargento que se reportava diretamente ao capitão comandante do distrito policial. Cada CPO ficou encarregado de cobrir uma determinada área urbana, seja residencial ou comercial. O papel desse policial diferia bastante dos policiais convencionais, o que lhes exigia maior flexibilidade de horários de trabalho e novas habilidades. Eram quatros as tarefas exigidas para cada policial: planejamento, avaliação e solução dos problemas, ligação com a comunidade e troca de informações (Farrell, 1988). Para isso, o policial deveria identificar os principais problemas enfrentados pela comunidade e era encorajado a buscar soluções para estes problemas. Com respeito à comunidade, esperava-se que o policial fosse capaz de envolver os cidadãos na identificação e resolução dos problemas. Por último, o policial deveria aproveitar sua maior proximidade com os problemas cotidianos para fortalecer as relações entre a polícia e a comunidade.

Por certo, essas mudanças no tipo de policiamento, bem como as inúmeras tarefas exigidas dos policiais encontrariam grandes dificuldades de implementação. Assim, o NYPD, solicitou também ao Vera Institute of Justice um estudo para avaliar o impacto desse programa, suas dificuldades, deficiências e propor soluções. A avaliação do programa iniciou-se em julho de 1986 e estendeu-se até fevereiro de 1988 (McElroy, Crosgrove \& Sadd, 1993).

O resultado dessa avaliação mostrou que a primeira tarefa de identificação dos problemas locais foi facilmente atendida pelo programa. Os problemas foram levantados com auxílio dos recursos estatísticos existentes e com a ampla colaboração da comunidade. Com relação à tarefa de avaliação e solução dos problemas, o estudo verificou que esse era o ponto mais fraco do programa. As ações que poderiam ser implementadas a partir dos próprios recursos do distrito 
policial e do departamento de polícia como um todo eram facilmente implementadas. Entretanto, os policiais encontravam dificuldades para planejar e implementar estratégias de ação que envolvessem a comunidade e outras agências estatais. Nesse ponto, o estudo verificou que era necessário maior apoio da comunidade e esforço organizacional para desenvolver essas tarefas. Em geral, como apontaram os autores, os cidadãos são mais preparados do que os policiais para a solução efetiva dos seus problemas, uma vez que esses últimos não foram especialmente treinados para essa função. O estudo sugeriu uma organização e preparação mais adequada para tratar do problema, assim foram criados os conselhos comunitários, visando integrar mais a comunidade à determinação das estratégias de ação.

Com relação ao impacto do programa nas relações entre a polícia e a comunidade, o estudo enfatiza:

As lideranças comunitárias são unânimes na crença de que as unidades do CPOP contribuíram significativamente na melhoria das relações entre a polícia e a comunidade. Elas acreditam que esses efeitos floresceram dos esforços dos policiais em procurar as pessoas, conversar com elas informalmente, comparecer aos encontros das organizações comunitárias, encorajar os moradores a comparecer a esses encontros e de fornecer informações sobre o que pode e o que não pode ser feito sobre criminalidade e problemas comunitários. A disposição de alguns policiais de admitir sua ignorância sobre um problema ou sobre os recursos que poderiam ser utilizados para resolvê-lo, e então buscar as informações necessárias e trazê-las de volta aos encontros comunitários, fortaleceu a credibilidade da polícia nessa vizinhança. (McElroy, Crosgrove \& Sadd, 1993, p. 69)

Em 1990, o novo prefeito, David Dinkins, e seu Comissário de Polícia, Lee Brown, tomaram o programa como sua principal política para a área de segurança pública. Para isso, incrementaram as modificações sugeridas pelo estudo do Vera Institute of Justice (Brown, 1991).

\section{"Tolerância Zero" e abuso de autoridade}

Em 1993, Rudolph Giuliani foi eleito prefeito de Nova Iorque, derrotando o antigo prefeito David Dinkins com uma plataforma 
centrada nos problemas de segurança pública, na melhoria da qualidade de vida e na repressão à criminalidade. Junto com o Comissário de Polícia William Bratton, o novo prefeito implementou uma ambiciosa política de segurança pública que enfatizava a repressão aos delitos contra a qualidade de vida, tais como vandalismos, pichamentos, badernas nas ruas, pequenos furtos, etc. Essa política ficou conhecida como "tolerância zero". 5

Logo que assumiu seu posto, o Comissário Bratton deu claros sinais de que a nova ênfase recairia no combate aos pequenos delitos contra a qualidade de vida e realizou inúmeras substituições na hierarquia do departamento. Nos três primeiros meses da sua administração, demitiu quatro dos seis policiais de mais alta hierarquia e criou uma nova função para seu antigo assessor, Jack Maple, que passou a ser responsável pelas estratégias de controle da criminalidade. Além disso, Bratton, substituiu mais de 2/3 dos comandantes de distritos policiais (Silverman, 1999).

Feitas as mudanças no comando do NYPD, o novo comissário estabeleceu que as próximas promoções seriam baseadas na performance de cada policial e não mais na antigüidade na carreira. Os critérios de avaliação recairiam sobre o desempenho de cada distrito policial com relação às metas traçadas por Bratton e sua equipe. Para isso, o departamento de polícia passou a divulgar suas estratégias de policiamento. A primeira delas dizia respeito à apreensão de armas de fogo e os distritos policiais deveriam enfatizar as operações de busca e apreensão de armas de fogo (NYPD, 1994a). Outra estratégia destacava a repressão ao comportamento desviante de grupos jovens. Os comandantes de distrito deveriam enfatizar a detenção de jovens cujo comportamento tivesse alguma relação com delitos contra a qualidade de vida, principalmente vandalismos e badernas de rua (NYPD, 1994b).

Como todos os distritos policiais teriam seu desempenho avaliado a partir da sua performance nessas estratégias, houve necessidade de adequá-los à nova realidade. Para isso, os comandantes de distrito foram encorajados a deslocar suas unidades operacionais 
para a função de patrulhamento das ruas, que era anteriormente desempenhada por uma unidade especial (Street Crime Unit). ${ }^{6}$

Como resultado, a prática de abordar e revistar (stop and fisk) cidadãos cresceu substancialmente. A comissão de direitos civis do governo federal aponta que em 1989 a polícia tinha realizado cerca de 42 mil operações desse tipo e em 1998 esse número tinha alcançado aproximadamente 115 mil (EUA, 2000, p. 15). ${ }^{7}$ Os resultados dessa política repressiva têm sido firmemente criticados por diversas organizações, como a Anistia Internacional, Police Watch e New York Civil Liberties Union. Ao longo desta pesquisa, inúmeros membros dessas entidades foram entrevistados e todos compartilham a opinião de que essa estratégia policial serviu para agravar as relações entre polícia e determinadas comunidades, especialmente as negras e latinas, principais alvos da polícia.

Em março de 1999, quatro policiais da Street Crime Unit, numa operação de busca e revista, mataram o jovem africano Amadou Diallo com 41 tiros. A brutalidade da ação policial e o fato de não haver nenhuma razão que justificasse a operação causaram indignação na sociedade local. O episódio desencadeou uma série de protestos contra essa estratégia policial. Na primavera de 1999, mais de 1.200 pessoas, incluindo dois ex-prefeitos, lideranças negras, rabinos e cidadãos comuns submeteram-se a detenções policiais a fim de protestar contra o desrespeitos aos direitos civis por parte da polícia de Nova Iorque.

Num novo trabalho, em que discute os resultados das políticas adotadas em Nova Iorque, George Kelling comenta a questão dos direitos civis e os abusos de autoridade por parte da polícia (Kelling \& Coles, 1996). Para o autor de Broken Windows, boa parte dos problemas surgidos são decorrentes da falta de normas de conduta claras que disciplinem a ação policial. O autor cita como exemplo as normas impostas por Murphy para restringir o uso da força letal. Embora possamos concordar com a necessidade de regras limitadoras da ação policial, não acreditamos que a questão seja tão simples assim. Quando Murphy implantou suas regras de conduta, baseou-se na filosofia de proteção à vida. No caso da política de "tolerância zero", 
parece que há uma incoerência entre propor um papel mais agressivo à polícia e ao mesmo tempo sugerir maiores restrições à sua ação.

\section{O Civilian Complaint Review Board (CCRB) e o Controle Externo}

Até o início da década de 70, eram raros os departamentos de polícia norte-americanos que possuíam algum órgão de controle externo. Já em 1998, a situação era bastante diferente; podíamos encontrar mais de 90 agências de controle externo e cerca de $3 / 4$ dos 50 maiores departamentos de polícia possuíam um órgão controlador externo. ${ }^{8}$

Dois fenômenos estão relacionados ao surgimento dessas agências de controle. Em primeiro lugar, pode-se dizer que as pressões da sociedade civil, através dos movimentos de direitos civis, mostraram a necessidade de criação de agências de controle externo. Segundo, a necessidade percebida por alguns administradores de polícia de mudar a relação entre a polícia e a sociedade, buscando maior legitimidade para a atividade policial. Em ambos os casos, a criação de um órgão de controle externo parecia ser a solução mais adequada. Entretanto, dada a variedade de interesses envolvidos nesse processo, bem como as diferenças institucionais de cada departamento de polícia, a estrutura dessas agências de controle externo varia enormemente, tanto em relação à sua independência da polícia, quanto aos poderes a elas atribuídos.

O NYPD possuía um órgão supervisor, encarregado de investigar denúncias contra seus policiais desde de 1953. Inicialmente, o Civilian Complaint Review Board (CCRB) era constituído por três subcomissários encarregados de receber, investigar e relatar as denúncias ao Comissário de Polícia. Dada sua estrutura precária, o CCRB não era capaz de desempenhar satisfatoriamente as suas tarefas. ${ }^{9}$

Em 1986, o então prefeito Ed Koch, acatando um decisão do City Council (Câmara Municipal), nomeou seis civis, além dos outros 
seis policiais nomeados pelo Comissário de Polícia, para comporem o CCRB. No ano seguinte foram contratados os primeiros investigadores civis para auxiliarem os trabalhos dos demais policiais. Apesar dessas mudanças, o CCRB carecia de independência administrativa e financeira. Todo seu corpo burocrático era composto por policiais, bem como seu orçamento era vinculado ao departamento de polícia. Além disso, o órgão possuía reduzida autonomia operacional, uma vez que a maioria dos seus investigadores pertenciam ao NYPD.

Visando ampliar sua autonomia, em 1993, o prefeito David Dinkins introduziu uma série de reformas no CCRB. Em primeiro lugar, o conselho diretor (Board) foi ampliado de 12 para 13 membros, tendo sua composição alterada: 3 membros seriam nomeados pelo Comissário de Polícia, 5 indicados pelo City Council, que normalmente aponta um representante de cada região metropolitana, e outros 5 membros indicados pelo prefeito, que tem poder de veto sobre todas as indicações. Se por um lado essa nova composição deu maior autonomia ao CCRB em relação à polícia, por outro, manteveo sob influência do prefeito.

Além das alterações na composição do seu conselho diretor, o CCRB ganhou autonomia financeira e operacional. Desde então a agência possui equipe própria de investigadores e corpo administrativo, bem como é dotada de orçamento próprio. No final do 2000, o CCRB contava com 163 funcionários e 107 investigadores.

O CCRB é encarregado de investigar alegações de desvio de conduta policial envolvendo uso de força desnecessária, abuso de autoridade, descortesia e linguagem ofensiva. A agência tem jurisdição sobre a atividade de todos os membros do NYPD. Entretanto, ela não tem autoridade para impor sanções disciplinares, tampouco pode processar judicialmente o policial envolvido em crime. ${ }^{10}$

Uma vez recebida a denúncia de desvio de conduta policial, uma equipe de investigadores é encarregada de levantar provas que confirmem tal alegação. Coletadas as provas, o caso é submetido a uma turma do conselho diretor (5 membros) que disporá da seguinte 
forma sobre a denúncia: substanciada, quando há provas suficientes de que houve desvio de conduta policial; não-substanciada, quando não há provas suficientes para determinar o desvio de conduta; exonerada, quando o fato aconteceu mas não pode ser caracterizado como desvio de conduta policial, e não-encontrada, quando o fato não aconteceu.

Se a alegação for considerada substanciada, o conselho diretor encaminhará o caso ao Comissário de Polícia recomendando as seguintes medidas disciplinares:

a) Instruções - medidas disciplinares mais brandas, onde o policial é reconduzido a novas sessões de treinamento para corrigir erros e falhas na sua conduta diária;

b) Advertências - medidas disciplinares impostas pelo comandante, que podem variar de advertência verbal a perda de até 10 dias de férias;

c) Punições disciplinares - medidas disciplinares mais graves; constituem uma punição formal adotada pelo Departamento de Polícia e podem variar da perda de férias à expulsão do policial.

Tanto as instruções quanto as advertências são medidas disciplinares, que embora constem da ficha do policial, não têm validade legal.

Como vimos antes, o CCRB não pode tomar medidas disciplinares contra policiais, uma vez que isso é prerrogativa do Comissário de Polícia. A agência encarregada de administrar os processos disciplinares e assessorar o Comissário Geral nesses casos é a Unidade de Assessoramento Disciplinar (Disciplinary Assessment Unit - DAU). Recentemente as alegações substanciadas também têm sido enviadas para o Escritório de Advocacia do Departamento (Department Advocacy Officer - DAO) que pode mover ações judiciais contra os policiais. Um comitê interno do NYPD, composto por membros da DAU e do DAO delibera sobre os casos de alegações 
de desvio de conduta e recomenda ações disciplinares ao Comissário Geral.

Apesar de todas as mudanças ocorridas nos últimos anos, o trabalho do CCRB ainda apresenta uma série de deficiências, jé que menos da metade das denúncias recebidas, entre 1996 e 2000, foram plenamente investigadas pela agência (Tabela 2). Dessas, pouco mais de $10 \%$ foram substanciadas, ou seja, em menos de $6 \%$ das denúncias recebidas foram coletadas provas suficientes para tornar possível alguma sanção disciplinar.

Tabela 2 - Investigaçõs do CCRB - 1996-2000

\begin{tabular}{ccccc}
\hline Ano & $\begin{array}{c}\text { Reclamações } \\
\text { Recebidas }\end{array}$ & $\begin{array}{c}\text { Casos } \\
\text { Investigados (\%) }\end{array}$ & $\begin{array}{c}\text { Casos } \\
\text { Substanciados (\%) }\end{array}$ & $\begin{array}{c}\text { \% Casos Investigados } \\
\text { que foram Substanciados }\end{array}$ \\
\hline \hline & & & & \\
1996 & 5713 & 33,1 & 4,7 & 13,5 \\
1997 & 5579 & 56,3 & 8,0 & 14,3 \\
1998 & 5312 & 48,6 & 5,6 & 11,6 \\
1999 & 4299 & 47,3 & 6,4 & 13,5 \\
2000 & 4979 & 46,7 & 3,8 & 7,8 \\
Total & 25852 & 46,7 & 5,7 & 12,2 \\
\hline
\end{tabular}

Fonte: Civillian Complaint Review Board. Status Report: January-December 2000.

Essa dificuldade em "substanciar" as denúncias pode ser atribuída às dificuldades para investigar uma alegação de desvio de conduta. Em primeiro lugar, devido ao número limitado de investigadores, alguns casos são escolhidos por apresentarem maiores possibilidades de "substanciação". Além disso, a dificuldade de coletar provas nos padrões exigidos pelo NYPD limita ainda mais a capacidade investigativa do CCRB.

Outra limitação à tarefa desempenhada pelo CCRB é o baixo número de medidas disciplinares adotadas em função das suas investigações. Como mostra a Tabela 3, menos da metade dos casos substanciados são transformados em medidas disciplinares pelo NYPD, e nas alegações mais graves apenas a terça parte resultou em punição disciplinar. 
Tabela 3 - Efetividade das Investigações do CCRB 1996-2000

\begin{tabular}{lccc}
\hline \multicolumn{1}{c}{$\begin{array}{c}\text { Medidas } \\
\text { Recomendadas }\end{array}$} & $\begin{array}{c}\text { Policiais } \\
\text { Acusados }\end{array}$ & $\begin{array}{c}\text { Policiais Punidos } \\
\text { pelo NYPD }\end{array}$ & $\%$ \\
\hline \hline & & & \\
Punição Disciplinar & 935 & 338 & 36,1 \\
Advertência & 587 & 318 & 54,1 \\
Instrução & 192 & 118 & 61,4 \\
\hline Total & 1714 & 774 & 45,2 \\
\hline Fonte: & Civillian Complaint Review Board. Status Report: January-December 2000.
\end{tabular}

Parte dessas dificuldades são explicadas pelos diferentes critérios adotados pelo NYPD e pelo CCRB para determinar a veracidade das alegações contra policiais. Os critérios do departamento são mais rigorosos e tornam muito mais difícil a tarefa do CCRB. Além disso, há um limite de 18 meses, a contar da ocorrência do incidente, para a possibilidade de imposição de uma medida disciplinar. Como o tempo médio de conclusão das investigações do CCRB é de 15 meses, o NYPD tem alegado falta de tempo para avaliar e julgar os casos.

Portanto, apesar dos esforços para dotar o CCRB de maior autonomia e capacidade operacional, os resultados não têm sido muito encorajadores. Isso deve-se às dificuldades para conduzir investigações e punir individualmente cada caso de desvio de conduta. Embora importante, isso parece pouco eficaz no controle geral da atividade policial. Por outro lado, há um aspecto que tem sido negligenciado com relação ao potencial do CCRB para auxiliar os esforços de controle da polícia. São raras as recomendações feitas pela agência para que o NYPD adote ou mude suas normas de conduta. Uma das exceções foi o estudo feito pelo CCRB sobre o perigo da utilização de spray de pimenta com armamento não letal. Ponderouse que o uso desse tipo de armamento não letal poderia causar danos a saúde. Para isso, foram apresentados inúmeros pareceres médicos, comentando os possíveis danos à saúde. Apesar do seu esforço, o estudo não foi levado em consideração pelo NYPD. Além disso, o $\mathrm{CCRB}$ não conduz pesquisas junto às comunidades mais afetadas por ocorrências de desvio de conduta policial para verificar a natureza e 
as regularidades dessas condutas, a fim de poder propor soluções mais efetivas. Em entrevista dada ao autor, Debra Livingstone, professora de Direito da Columbia University e membro do CCRB, apontou que o órgão tem se ocupado muito mais da investigação de casos individuais do que avaliação das normas de conduta.

\section{A Justiça e o controle da atividade policial}

A exemplo de outros países, nos EUA também são raros os casos de policiais punidos judicialmente por abuso de autoridade e excessivo uso da força. Em entrevista dada ao autor, Peter Neufield, conhecido advogado especialista em litígios contra brutalidade policial em Nova Iorque, reconheceu que são pouquíssimos os casos de condenação de policiais por violência contra cidadãos. São dois os mecanismos jurídicos possíveis, a ação penal e a ação civil. Entretanto, como afirma Mary Cheh, os processos civis e penais não têm desempenhado papel relevante no controle da atividade policial (Cheh, 1996).

O processo penal só pode ser utilizado contra indivíduos, nunca contra instituições, e está limitado por uma série de formalidades processuais. São dois os principais motivos alegados para a sua pouca eficiência no controle da atividade policial. Primeiro, num processo penal, o acusado goza de inúmeras vantagens processuais. Deve-se provar sua culpa "além da razoável dúvida". O acusado também pode solicitar mudança de fórum do seu processo (change of venue) quando o lugar de seu julgamento lhe parecer desfavorável e hostil. Isso tem acontecido freqüentemente nos incidentes envolvendo policiais brancos e vítimas negras. Não raro, o julgamento é transferido do fórum onde aconteceu o incidente, normalmente uma comunidade negra ou latina, para um fórum mais distante, menos hostil aos policiais e supostamente neutro. De fato, isso tem servido para absolver policiais acusados de violência policial, como no caso dos policiais que mataram com 41 tiros o jovem negro Amadou Diallo. O caso aconteceu em Nova Iorque, mas foi transferido para Albany, a capital do Estado. Lá, um júri predominantemente branco inocentou os policiais da acusação de uso de violência desnecessária. $\mathrm{O}$ mesmo aconteceu no 
caso do motorista negro Rodney King, em Los Angeles, em 1994. Um júri composto majoritariamente por brancos inocentou os policiais acusados de espancar King alegando faltas de provas, apesar do incidente ter sido filmado por um cinegrafista amador. $\mathrm{O}$ veredicto do júri causou revolta à população negra e deflagrou um onda de violentos protestos que causou prejuízos de algumas centenas de milhões de dólares e terminou com a intervenção do exército na cidade.

Um segundo fator que tem contribuído para a pouca utilidade do sistema de justiça criminal no controle da atividade policial é a relutância de algumas autoridades, principalmente promotores de justiça (District Attorneys - DA's) de processarem policiais. Parte dessa relutância pode ser explicada pelo tipo de relação entre o ministério público e a polícia. Não há uma relação de hierarquia entre essas duas instituições, embora ambas precisem trabalhar em estreita colaboração. Dessa forma, se a polícia quiser atrapalhar o trabalho de determinado promotor, pode fazê-lo e este sofrerá um desgaste desnecessário dentro de sua carreira. Com vistas a resolver esse problema, algumas entidades ligadas à promoção dos direitos humanos em Nova Iorque, têm proposto a criação de promotores especiais, designados exclusivamente para tratar dos casos de desvio de conduta policial (New York Civil Liberties Union, 1998; Green et al., 2000).

No caso de Nova Iorque, há um outro problema. A legislação estadual determina que um funcionário público só poderá ser interrogado 48 horas após o incidente no qual é acusado de desvio de conduta. Isso tem servido para que nesse período, os policiais envolvidos em casos de desvio de conduta acertem seus depoimentos e apresentem testemunhas com depoimentos que lhes sejam favoráveis. Também nesse caso, algumas entidades tem defendido o fim de tal prerrogativa.

Outro problema do uso da justiça penal no controle da atividade policial é que nos raros casos em que possa punir policiais, a justiça penal não é capaz de impor mudanças fundamentais na relação entre a polícia e a sociedade. Pelo contrário, às vezes serve para perpetuar 
uma determinada estrutura institucional e um padrão de comportamento ao enfocar apenas a dimensão individual do problema.

Em função dessas dificuldades, alguns autores têm argumentado sobre a possibilidade do uso da justiça civil para impor sanções aos departamentos de polícia, uma vez que a legislação norte-americana ampara o uso do processo civil nos casos de violações dos direitos civis por parte de autoridades públicas (Chevigny, 1995; Cheh, 1996). Dada a natureza do sistema jurídico norte-americano, os meios de provas exigidos num processo civil são menos rígidos do que nas ações penais, uma vez que impõem apenas a "preponderância da evidência" ao invés do nível "além da dúvida razoável". Além disso, o acusado e o ministério público podem escolher a forma de ação, bem como o fórum para julgá-la. Tampouco o recurso da ação civil impede o uso da ação penal.

No caso de Nova Iorque, como Paul Chevigny (1995) aponta, embora o número de sentenças determinando indenizações por parte do NYPD tenha crescido nas últimas duas décadas, isso não têm servido para mudar comportamentos institucionalizados. As razões talvez sejam os custos relativamente baixos dessas indenizações. Entre 1987 e 1992, Chevigny calcula que o NYPD pagou cerca de US\$ 50 milhões em indenizações civis, o que é pouco se comparado com seu orçamento acumulado nos mesmos anos de quase US\$ 1 bilhão. Além disso, o departamento de polícia pode solicitar aumento no seu orçamento, incluindo uma quantia destinada ao pagamento de tais indenizações.

Em julho de 2001, a justiça civil de Nova Iorque determinou que o NYPD pagasse 7,1 milhões de dólares a Abner Louima, um jovem negro que fora torturado e abusado sexualmente por quatro policiais num distrito policial no bairro do Brooklyn, em 1997. Apesar do elevado valor da indenização, o departamento de polícia deverá pagar a indenização a Louima em cotas mensais de US\$ 5.000,00 durante 20 anos, o restante será pago aos advogados da vítima, descontados os impostos devidos. ${ }^{11}$ Dificilmente esse valor irá obrigar o NYPD a rever seus procedimentos e, provavelmente, nos próximos 
anos essa indenização fará parte do orçamento do departamento. Entretanto, o caso Louima trouxe uma novidade no campo dos litígios civis. Pela primeira vez uma organização civil, o sindicado dos policiais (Police Benevolent Association - PBA) foi condenada a pagar uma indenização por tentar encobrir casos de violência policial.

\section{Os procuradores federais e o controle das polícias}

Tradicionalmente, a atividade policial norte-americana é tratada como um assunto basicamente municipal, com algumas implicações estaduais. A maior parte do trabalho policial é desempenhado pelos departamentos de polícia municipais e algumas tarefas de patrulhamento de estradas, manutenção e administração do sistema carcerário são atribuídas às polícias estaduais. Os governos federais têm procurado se manter a distância de problemas relativos à criminalidade e ao controle da atividade policial e, assim, têm se mostrado relutantes em interferir de alguma forma nos departamentos de polícia.

Entretanto, como vimos, algumas decisões da suprema corte federal têm afetado diretamente a atividade policial, uma vez que impõem novos padrões de conduta policial. Mesmo assim, a suprema corte não tem estabelecido regras de conduta mais específicas para o trabalho policial, tampouco tem se mostrado decidida a interferir diretamente nos assuntos internos dos departamentos de polícia.

Depois das graves repercussões do incidente com Rodney King, em 1994, algumas medidas começaram a ser implantadas pelas autoridades federais. O departamento de justiça, através do seu Bureau of Justice Statistics (BJS), vem realizando, ao longo das últimas décadas, um extraordinário trabalho de coleta e disseminação de dados sobre criminalidade, sentenças judiciais, administração da justiça e sistema penitenciário. Até 1994, o BJS não possuía nenhuma informação sobre violações aos direitos humanos, desrespeito aos direitos civis e desvio de conduta policial. A partir de 1995, o BJS começou a coletar informações sobre a atividade policial. Entretanto, 
as deficiências desse tipo coleta de dados têm dificultado bastante a realização de estudos sobre o tema, bem como a monitoração da atividade das diversas polícias norte-americanas.

Outra iniciativa tomada pelas autoridades federais foi a aprovação de uma lei que possibilitou ao ministério público federal a condução de investigações sobre "práticas e condutas" policiais que violassem a Constituição ou qualquer outra lei federal. Para Mary Cheh (1996, p. 257), essa lei poderá desempenhar um importante papel na proteção dos direitos individuais dos cidadãos, porque além de reconhecer que a justiça local pode não ser tão eficaz no controle da atividade policial, também permite um segundo nível de supervisão dessa atividade. Entretanto, no entender de outro especialista no assunto, Paul Chevigny (1995, p. 110-116), a capacidade de o governo federal exercer um controle efetivo sobre as policias norte-americanas e assegurar a proteção dos direitos humanos dos seus cidadão continua bastante reduzida.

\section{Conclusão}

Das reformas implantadas no NYPD, as que estabeleceram ou modificaram normas internas de conduta foram as que mais afetaram as relações entre a polícia e a sociedade. São as normas de conduta que estabelecem os padrões desejados de conduta do policial e sua interação com a sociedade. Os programas de treinamento são estabelecidos a partir dessas normas de conduta e visam capacitar os policiais a agir dentro de determinados padrões de comportamento. Ao contrário do que se pensa, não são os programas de treinamento que modificam a conduta policial, mas a estrutura institucional é que estabelece padrões esperados de condutas. Nesse sentido, a criação de normas que limitaram significativamente o uso de armas de fogo foram medidas importantes para o controle das forças policiais. No exemplo mostrado, a criação de normas claras para a utilização de armas de fogo permitiu que o treinamento fosse adequado às novas exigências, bem como possibilitou uma melhor fiscalização por parte dos comandantes de polícia. 
Outra medida institucional de grande impacto na comunidade foi a mudança na filosofia e na estratégia de policiamento com implantação do programa de policiamento comunitário. Essa nova estratégia de atuação policial implicou profundas mudanças internas na estrutura policial e implantou novos padrões de conduta policial, acarretando um maior envolvimento da comunidade nas políticas de segurança pública, bem como aproximou-a mais da polícia. Para tal, foi necessário reorganizar internamente os distritos policiais e treinar os policiais a partir das novas condutas esperadas. Por outro lado, a implantação do programa "tolerância zero" acirrou as relações entre a polícia e a comunidade.

Outra medida que teve forte efeito sobre a conduta policial foi a mudança na legislação criminal no que tange aos interrogatórios policial. Nesse caso, os limites impostos pela suprema corte federal ao uso de interrogatórios nos processos criminais fizeram com que as polícias adequassem suas práticas à nova realidade. Pode-se dizer que essas decisões judiciais tornaram inviáveis determinadas condutas policiais.

Se tais medidas foram eficazes na mudança de certas condutas policiais, o mesmo não se pode dizer com relação à criação de um órgão de controle externo, à maior utilização da justiça e à criação de procuradores independentes. Em boa medida, isso pode ser explicado pela excessiva ênfase na punição individual dos policiais. Não há dúvida de que sistemas disciplinares, internos ou externos, sejam importantes para o cumprimento de certas normas de conduta. Entretanto, nesse caso, o que se espera do policial é a adequação da sua atividade às normas de conduta já estabelecidas. Esse tipo de medida é bastante útil quando o problema repousa no desvio de conduta individual de certos policiais. Entretanto, quando se trata de mudar as relações entre a polícia e a sociedade como um todo, a ênfase deve ser dada a mudanças nas normas gerais de procedimento. 


\section{Notas}

1 As dificuldades de implementação das reformas foram discutidas no seminário " Police Reform and International Community: From Peace Process to Democratic Governance “, em 14 de novembro de 2001. O encontro foi organizado pela ONG Washington Office on Latin America (WOLA) e pela Escola de Estudos Internacionais Avançados (School of Advanced International Studies - SAIS), da Universidade John Hopkins, Washington, D.C.

2 As traduções encontradas neste texto são de inteira responsabilidade do autor.

3 The New York Times, 2 July 2001, p. A 12.

4 Uma rara exceção era o Federal Bureau of Investigations (FBI) que, desde a década de 40, possuía normas estritas para o uso de armas de fogo por parte dos seus agentes.

5 O programa "tolerância zero" foi inspirado num artigo de James Q. Wilson e Geoge Kelling (1982), no qual fazem a seguinte analogia: "Se uma janela de um prédio é quebrada e não é consertada, todas as outras janelas logo serão quebradas também (...) Uma janela deixada sem conserto é um sinal de que ninguém se preocupa, e de que quebrar mais janelas não custará nada" (p. 31). Assim, a ênfase do policiamento deveria recair sobre delitos de menor gravidade. Nesse sentido, a presença mais constante da polícia nas comunidades afetadas, inibindo os pequenos delitos, deveria ser encarada como peça fundamental nas novas estratégias de policiamento.

6 Além disso, a Street Crime Unit teve seu tamanho triplicado de 138 oficiais, em 1997, para 438, em 2000.

7 Estima-se que estes números sejam ainda maiores, uma vez que nem todas as operações são relatadas pela polícia.

8 Sou grato a Benjamim Reames por estas informações.

9 Uma primeira tentativa de reformar o órgão aconteceu em 1966. O prefeito John Lindsay nomeou quatro civis para compor o conselho diretor do órgão (Board). Um ano depois, em conseqüência da onda de protestos conduzida pela polícia e por grupos a ela ligados contra a intromissão civil nos assuntos internos da polícia, o prefeito viu-se obrigado a voltar atrás na decisão.

10 A partir de 2003, o CCRB foi autorizado a processar diretamente os policiais acusados de crimes.

11 The New York Times, 13 July 2001, p. B 4. 


\begin{abstract}
The control of police activities is one the main aspects of democratic regimes. It is necessary, therefore, a debate on the types of proposed measures to control the polices. Aiming to contribute to the debate, this article analyses some institutional reforms, both internal and external to the New York Police Department and its effects on the relationship between the police and the society. We realized that the reforms aiming to change some police institutionalized practices were more successful than those that focused on the individual punishment of misconduct.
\end{abstract}

Key-words: police violence, control of police activities, democracy, New York Police Department, police.

\title{
Referências bibliográficas
}

AMNESTY INTERNATIONAL. Police brutality and excessive force in New York City Police Department. New York: Amnesty International, 1996.

BAYLEY, David. The police and political development in Western Europe. In: TILLY, Charles (Org.). The formation of national States in Western Europe. Princeton: Princeton University Press, 1975. p. 328-379

BAYLEY, David; GARAFALO, James. The Manegement of Police Patrol Officers. Criminology, v. 27, n. 1, p. 1-23, 1989.

BROWN, Lee. Policing New York in the 1990's: the strategy for community policing. New York: New York City Police Department, 1991.

CHEH, Mary. Are lawsuits an answer to police brutality? In: GELLER, William; TOCH, Hans. Police violence; understanding and controlling police abuse of force. New Haven: Yale University Press, 1996.

CHEVIGNY, Paul. Police power: police abuses in New York City. New York, Pantheon, 1969.

. Edge of the knife: police violence in Americas. New York: Free Press, 1995.

FARRELL, Michael. The development of the Community Officer Program: community oriented policing in the New York City Police Department. GREENE; MASTROSFSKI. (Eds.). Community policing: rhetoric or reality. New York: Praeger, 1988. p. 73-88. 
FYFE, James. Shots fired: a typological examination of New York City Police Firearms Discharges, 1971-1975. 1978. SUNY, Tese de Doutorado.

GELLER, William; SCOTT, James. Deadly force: what we know, a practitioner's desk reference on police-involved shootings. Washington: Police Executive Research Forum, 1992.

GREEN, Mark et al. Disciplining police: solving the problem of police misconduct. New York: Office of The New York City Public Advocate, 2000 .

IMMERGUT, Ellen M. The theoretical core of the new institutionalism. Politics and Society, v. 26, n. 1, 1998.

KAMISAR, Yale. Police interrogations and confessions: essays in Law and Police. Ann Arbor: University of Michigan Press, 1990.

KELLING, George; COLES, Catherine. Fixing broken windows: restoring order and reducing crime in our communities. New York: Free Press, 1996.

KNAPP COMMISSION. Report on Police Corruption. New York: George Braziller, 1972.

MARCH, James; OLSEN, Johan. The new institutionalism: organizational factors in political life. American Political Science Review, v. 78, n. 3, 1984.

McELROY, Jerome; COSGROVE, Colleen; SADD, Susan. Community policing: the CPOP in New York. Newbury Park, CA: Sage, 1993.

MOLLEN COMMISSION. Commission to Investigate Allegations of Police Corruption and Anti-Corruption Procedures of Police Department Report. New York, 1994. Mimeografado.

NEW YORK CIVIL LIBERTIES UNION. Defletcting blame: the dissenting Report of the Mayor's Task Force on Police/Community Relations. New York: NYCLU, 1998.

NYPD. Patrol guide. New York: NYPD, 2000. . Police strategy $n^{\circ}$ 1: getting guns off the streets. New York: NYPD, 1994a.

. Police strategy $n^{\circ} 2$ : curbing youth violence in the schools and on the streets. New York: NYPD, 1994b.

SILVERMAN, Eli. NYPD battles crime: innovative strategies in policing. Boston: Northeastern University Press, 1999. 
SKOLNICK, Jerome; FYFE, James. Above the Law: police and the excessive use of force. New York: The Free Press, 1993.

UNITED STATES COMMISSION ON CIVIL RIGHTS. Police practices and civil rights in New York City: a report. Washington-DC, 2000. Mimeografado.

WILSON, James Q.; KELLING, George. Broken windows: the police and neighborhood safety. The Atlantic Monthly, n. 249, p. 29-38, 1982. 